\title{
Estudo e Implementação de Técnicas de Motivação no Moodle
}

\author{
Samanta F. Aires ${ }^{1} \quad$ Jair C. Leite ${ }^{1,2}$ \\ ${ }^{1}$ Instituto Metrópole Digital - Universidade Federal do Rio Grande do Norte (UFRN) \\ Caixa Postal 1524 - 59.078-970 - Natal - RN - Brasil \\ ${ }^{2}$ Departamento de Informática e Matemática Aplicada - Universidade Federal do Rio \\ Grande do Norte (UFRN) \\ Caixa Postal 1524 - 59.078-970 - Natal - RN - Brasil \\ jair@dimap.ufrn.br, samantaferaires@gmail.com
}

\begin{abstract}
One of the greatest issues faced by distance education is a lack of interaction among students and among them and their teachers/tutors. Virtual learning environments (VLE) have emerged in an attempt to improve this problem with interaction tools such as forums and chats. Nevertheless, even with these tools, there is still no great interactivity among users of these environments. Therefore, in this project, we presentations the stages of study, formulation, implementation and results of the application of some techniques of motivation based on rewards and recognition, that aim to increase a collaboration and participation of the students within VLE Moodle of a technical course. We evaluate the impact of the techniques by directly assessing the use of the system to read and write in the discussion forums. As a conclusion, we discuss the results and we point how the use of such techniques requires a very well planning, particular in the education domain.
\end{abstract}

Resumo. Um dos maiores problemas enfrentados pela Educação a distância, é a falta de interação entre os alunos, e entre eles e seus professores/tutores. Os ambientes virtuais de aprendizagem (AVAs) surgiram na tentativa de melhorar esse problema através de ferramentas de interação, como os fóruns e os chats. Entretanto, mesmo com essas ferramentas, ainda vemos que não há grande interatividade entre os usuários desses ambientes. Dessa forma, neste projeto, apresentamos as etapas de estudo, formulação, implantação e resultados da aplicação de algumas técnicas de motivação baseadas em recompensas e reconhecimento, que objetivam aumentar a colaboração $e$ participação dos alunos dentro do AVA Moodle de um curso técnico. $O$ impacto das técnicas foram avaliadas pela análise do uso do sistema para postar e comentar nos fóruns de discussão. Ao final, discutimos os resultados $e$ indicamos que o uso destas técnicas, particularmente em ambientes de ensino, precisa ser bastante planejado.

\section{Introdução}

A Educação à Distância (EAD) ganha cada dia mais força e difere-se das metodologias tradicionais de ensino, com o aprendizado baseado no autodidatismo e na 
autodisciplina, mas apresentando baixa interatividade entre os alunos, com poucas possibilidades de troca de informação entre aprendizes e tutores [Knihs,2007].

A interação e a colaboração são fatores de extrema importância nos cursos à distância, e a sua prática deve ser estimulada no ambiente virtual, para que os alunos possam organizar suas ideias e compartilhar seus conhecimentos, tornando-se assim sujeitos autônomos de sua aprendizagem [Mehlecke e Tarouco 2011]. Hamari e Koivisto (2013) afirmam que as interações mantidas entre os indivíduos são fatores motivacionais para alguns deles. Isso se deve ao fato de que algumas pessoas acreditam que os outros esperam que elas se comportem de determinada maneira. Tipicamente, pessoas sentem-se recompensadas quando correspondem a essas expectativas, pois suas ações foram socialmente aceitas, e geraram um reconhecimento positivo.

Aplicando esse conceito na EAD, os ambientes virtuais de aprendizagem, tais como o Moodle, oferecem recursos para promover a interação e a colaboração entre os estudantes. Ferreira (2013) afirma que as ferramentas oferecidas pelos AVAs, propiciam a construção do conhecimento coletivo através da comunicação e interação, consideradas atitudes que estimulam os alunos.

Mesmo sendo de extrema importância, a interação e a colaboração entre os alunos de um curso a distância é muito baixa, o que contribui para que o número de evasão seja grande. Isso foi constatado no caso do uso do Moodle em cursos técnicos de Tecnologia da Informação para alunos de 15 a 20 anos, oferecidos pelo Instituto Metrópole Digital, da Universidade Federal do Rio Grande do Norte.

Para tratar deste tipo de problema, os sistemas colaborativos buscam formas de motivar seus alunos a colaborarem através de estratégias e técnicas de motivação. Por exemplo, as ferramentas de ensino de idiomas Livemocha (livemocha.com) e Busuu (busuu.com), fazem uso de elementos da gamificação para isso.

A gamificação, que é a utilização de elementos de design de jogos em contextos não relacionados a jogos [Deterding 2011], é uma técnica de motivação que está sendo aplicada nos mais diversos domínios. Um dos principais campos de experimentação dessa técnica é a educação. Fardo (2013) considera a gamificação como uma área bastante fértil de aplicação na educação, visto que propõe novas estratégias para dar conta de aprendizes que estão cada vez mais inseridos no contexto das mídias e das tecnologias digitais e se mostram desinteressados pelos métodos passivos de ensino utilizados no cotidiano escolar.

No entanto, apesar da utilização em vários softwares educacionais, pouco se tem visto da utilização dessa técnica em ambientes virtuais de aprendizagem [Alves 2013]. Isto se deve ao fato de que são necessários critérios bem definidos na escolha dos elementos dos games que sejam apropriados aos diversos segmentos de atividades pedagógicas no intuito de chamar a atenção e motivar o usuário [Roque 2013] a colaborar dentro do sistema.

A gamificação vem ganhando força, mas ela não é a única técnica de motivação existente. Algumas outras técnicas sobre reconhecimento e reciprocidade [Hamari e Koivisto 2013], também podem ser aplicadas nos sistemas educacionais. Essas técnicas baseiam-se principalmente na afirmação de que quando um usuário recebe um retorno 
(feedback) positivo, ele sente-se motivado a também dar retornos sobre as ações dos outros usuários, expandindo dessa forma a interação e a colaboração dentro dos AVAs, essenciais ao ensino à distância. Nesse projeto, separamos as técnicas estudadas em duas categorias: técnicas baseadas em recompensas (gamificação) e técnicas baseadas em reconhecimento.

Esse projeto toma como estudo de caso o AVA Moodle, modificado para atender ao curso técnico semipresencial de Tecnologia da Informação do Instituto Metrópole Digital (IMD) da UFRN. Esse ambiente já oferece alguns mecanismos de interação, como fóruns e chats, que podem ser utilizados para a colaboração entre os estudantes e entre eles e tutores. O escopo da nossa pesquisa está limitado à colaboração nos Fóruns do Moodle IMD, os quais possuem baixa utilização como observamos em pesquisa realizada com seus usuários.

Neste artigo, apresentamos resultados de um estudo feito com as técnicas de motivação que foram implementadas no Moodle IMD com o objetivo de verificar o aumento da participação e da colaboração nos fóruns. A seção 2 apresenta alguns trabalhos relacionados que implementaram técnicas semelhantes. A seção 3 introduz os fundamentos teóricos e a seção 4 descreve como as técnicas foram definidas e implementadas no Moodle IMD. As seções 5 e 6 descrevem a metodologia e os resultados do estudo. As conclusões estão na seção 7.

\section{Trabalhos relacionados}

Diversos projetos vêm sendo desenvolvidos tomando o AVA Moodle como estudo de caso. Esses projetos visam aplicar principalmente mecanismos de gamificação ao ambiente virtual, com o objetivo de motivar os usuários a colaborarem e a se engajarem nas atividades do sistema.

Um desses projetos estudou sobre a possibilidade de aplicação de badges (medalhas) ao Moodle, entretanto o estudo não foi realizado diretamente com os usuários do Moodle, e sim através do autor, que assumiu os diferentes papéis de usuário [Alves 2013]. Outro estudo propõe a implementação de um bloco gamificado, com rankings, níveis e barras de progresso, com o objetivo de motivar a resolução de problemas e encorajar a aprendizagem pelos alunos [Roque 2013]. Entretanto, não é explicitado como ou se é realizada a implantação desse bloco ou mesmo os resultados dessa aplicação obtidos junto aos alunos. Verificamos a mesma situação em um terceiro projeto que propõe uma interface gamificada, com o objetivo de engajar mais os usuários no sistema, estimulando-os no processo de educação à distância [Faleiros 2015]. Mas também não vemos a aplicação dessa interface e seus resultados.

Ao analisarmos esses trabalhos verificamos diversas propostas de aplicação de elementos da gamificação ao ambiente Moodle, mas em nenhum dos projetos estudados vimos o processo de implantação ou os resultados obtidos com ela.

Tomando como base as propostas acima e as técnicas de motivação estudadas da literatura, vimos diversas possibilidades de ampliação da interação e colaboração dos alunos do Moodle aqui estudado. Com isso definimos, junto aos responsáveis pelo ambiente virtual e pelos cursos técnicos oferecidos, alguns elementos referentes a essas 
técnicas para serem implantados no Moodle, com o objetivo de aumentar a colaboração dentro desse ambiente.

\section{Técnicas de motivação}

Através de uma pesquisa literária, identificamos a existência de diversas técnicas que estimulam a interação e a colaboração entre indivíduos dentro de um sistema computacional. Fizemos a separação dessas técnicas em duas: técnicas baseadas em recompensas, que referem-se ao uso de elementos da gamificação; e técnicas baseadas em reconhecimento, em que o usuário recebe feedbacks de outros usuários sobre suas ações no sistema.

\subsection{Técnicas baseadas em reconhecimento}

As técnicas baseadas em reconhecimento estão relacionadas à motivação social, na qual o estímulo do usuário é gerado principalmente através da opinião que os outros têm sobre suas ações. Para esses usuários, o reconhecimento que recebem sobre suas ações dentro do sistema é algo estimulante, principalmente se for positivo, e faz com que queiram também dar seu feedback para outros usuários.

Para esse tipo de usuário, as técnicas utilizadas devem ser de caráter social, possibilitando que outros usuários consigam dar feedbacks sobre suas ações, como por exemplo, a possibilidade de deixar comentários e "gostar" de alguma ação realizada. Esses são exemplos de duas técnicas de reconhecimento.

Os comentários permitem que usuários expressem melhor sua opinião sobre alguma ação realizada por outro usuário, como por exemplo, deixando sua opinião sobre um conteúdo compartilhado, uma foto, um pensamento, etc. Dessa forma, o usuário que recebe a opinião sobre seu conteúdo fica ciente se aquele tema é socialmente aceito para uso no sistema. Assim, se os comentários forem positivos, então ele sente-se mais estimulado e tenderá a compartilhar mais conteúdos semelhantes, e se os comentários forem negativos, ele hesitará em compartilhar temas semelhantes, buscando temas mais apropriados e interessantes, com o intuito de receber feedbacks positivos.

Já a opção gostar normalmente é utilizada através de um botão, e possui diversos rótulos, podendo ser gostar, curtir, favoritar, amar, entre outros. O Facebook utilizou o botão curtir por muito tempo, mas percebeu que a interação dentro do ambiente ia muito além da opinião de curtir ou não uma publicação, pois seus usuários necessitavam de outras opções que representassem seus sentimentos para com as publicações de seus amigos. Dessa forma, em 2016, foi lançada uma atualização com os botões de reações, adicionando-se as opções para amar, rir, se surpreender, expressar tristeza ou raiva em uma publicação através dos botões amei, haha, uau, triste e grr, respectivamente. Possibilitando que os usuários deem tanto feedbacks positivos, como negativos.

Esses botões de reações podem ter mesma finalidade dos comentários, que é oferecer um feedback ao usuário, sendo uma maneira mais rápida de fazer isso, pois nos 
comentários ainda toma-se tempo para escrever algo, mas com os botões de reações já existe uma grade de opções simples que representam a opinião dos usuários, que podem apenas clicar na opção que se relaciona a sua opinião.

\subsection{Técnicas baseadas em recompensas}

As técnicas baseadas em recompensas, como o nome já diz, tem como objetivo recompensar o usuário por uma ação realizada dentro do sistema. Essas recompensas são baseadas nos elementos de jogos, por isso os sistemas baseados nessas técnicas são considerados sistemas gamificados.

Os elementos de recompensas que são mais utilizados são os PBL (Points, Badges e Leaderboards ou Pontos, Medalhas e Rankings). Esses elementos são implantados nos sistemas com a finalidade de oferecer recompensas aos usuários por ações predeterminadas. Normalmente, as ações que oferecem recompensas são aquelas que devem ser mais realizadas pelos usuários. Por exemplo, o StackOverflow (stackoverflow.com), fórum de discussão sobre desenvolvimento, faz uso dos PBL para recompensar seus usuários quando eles realizam diversas ações dentro do sistema, como elaborar, responder e votar em uma perguntar.

Segundo Grant e Betts (2013), a utilização de elementos de gamificação, como os PBL podem influenciar o comportamento dos usuários, pois muitas vezes suas ações são mudadas apenas para conseguirem ganhar essas recompensas. Entretanto, nem sempre as recompensas trazem resultados positivos para os sistemas aos quais são adicionadas, e por isso devemos sempre analisar qual o objetivo da utilização desse mecanismo, para que sua conquista seja de acordo com o objetivo a ser atingido.

Os pontos são os elementos mais comuns dos jogos e normalmente são acompanhados de outros elementos do tipo recompensa. Quando utilizados dentro de um sistema que não é um jogo, os pontos são dados para tarefas que os administrados desejam que os usuários realizem. Além disso, muitos sistemas fazem uso tanto de pontos positivos, como pontos negativos, que são dados quando o usuário realiza alguma atividade que não deveria dentro do sistema, infringindo alguma regra, por exemplo.

Quando acumulados, os pontos podem gerar outras recompensas, dependendo do sistema, por exemplo, pode-se dar medalhas para o usuário quando ele atingir determinados valores em sua pontuação. As medalhas também são recompensas dadas quando se deseja que o usuário realize determinadas tarefas dentro do sistema. Tomando novamente como exemplo o StackOverflow, esse sistema possui uma complexa distribuição de medalhas. As medalhas são divididas hierarquicamente e são distribuídas aos usuários quando estes realizam tarefas específicas e de acordo com o nível do usuário e da tarefa.

O acúmulo de pontos e medalhas também pode gerar um ranking. Os rankings normalmente são utilizados em um sistema como uma motivação visual para os usuários, apresentando para eles sua colocação em relação aos outros. Esse tipo de 
elemento promove a competitividade entre os usuários, além de ser considerado um elemento de grupos [Fardo 2013]. Dessa forma é considerado motivador principalmente para os usuários competitivos, que veem sua posição no ranking como um estímulo para realizar as tarefas que farão com que ele atinja colocações mais elevadas.

\section{Aplicação no Moodle IMD}

Levando em consideração que o Moodle possui fóruns e a possibilidade de fazer comentários em tópicos desses fóruns, desenvolvemos os botões de reações para que os usuários pudessem também oferecer o feedback social de forma mais imediata. Esses botões estão aplicados a todos os fóruns do Moodle, possibilitando que o usuário reaja a um tópico ou comentário publicado, dando assim um retorno mais rápido sobre o conteúdo abordado. Esses botões oferecem sete opções de reação, sendo elas Obrigado, Gostei, Não gostei, Não entendi, Relevante, Inadequado e Top, representadas pelos ícones mostrados na Figura 1.

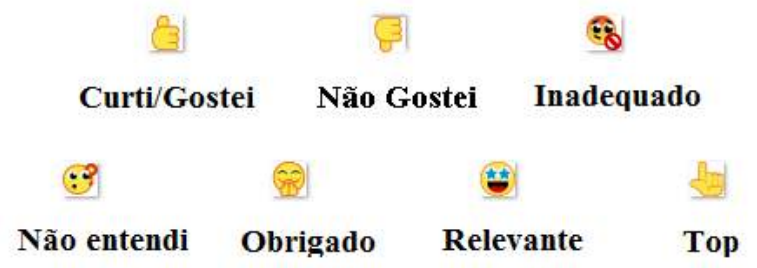

Figura 1. Ícones representando as opções de reações dos botões inseridos nos fóruns.

As escolhas dos botões foram baseadas nos principais comentários deixados pelos alunos nos tópicos vistos numa análise de vários comentários nos fóruns do Moodle. Na Figura 2.a e 2.b, apresentamos a interface dos fóruns antes e depois da implantação dos botões, respectivamente.

Peque Tópico para discutir sobre a engine proposta pelo professor

8\% por Christopher Matheus Florencio Ramos Neves - sexta, 18 Set 2015, 09:35

Unity!

Construct 2!

Os dois!

Figura 2a. Interface dos fóruns (tópico e comentário) antes da implantação dos botões. 


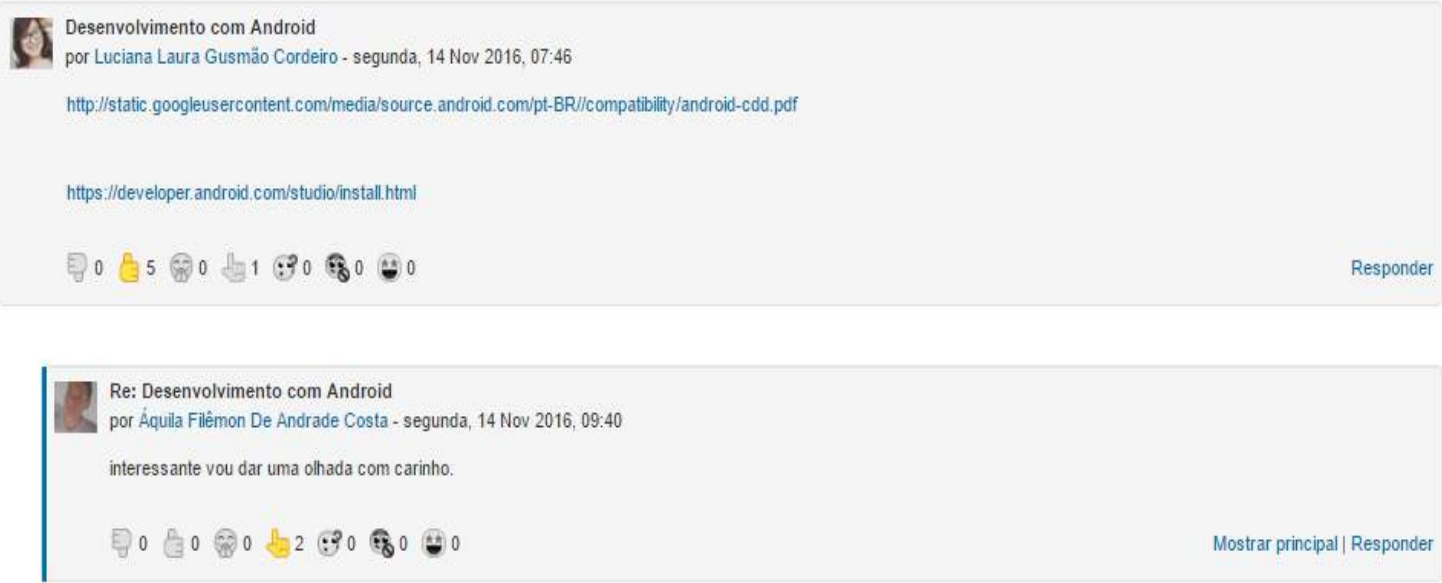

Figura 2b. Interface dos fóruns (tópico e comentário) após a implantação dos botões.

Dois meses após a implantação desses botões aos fóruns, foi adicionado o ranking. A contabilização dos pontos para elaborar o ranking foi feita através das reações, em que para cada reação recebida em uma publicação, o autor desta ganha 1 ponto, podendo ser positivo ou negativo, dependendo da reação. As reações Gostei, Obrigado, Relevante e Top geram pontos positivos, enquanto que Não entendi e Inadequado, geram pontos negativos.

A pontuação das reações passou a ser contabilizada desde a implantação delas, mesmo que sem o elemento ranking estar visível para os alunos. Assim, quando introduzimos o ranking os usuários já possuíam os pontos referentes às suas reações. $O$ ranking contabiliza pontos semanais, mensais e um geral, isto é, de todo o período ativo, assim as colocações são mais dinâmicas. Na Figura 3, conseguimos ter uma visão melhor desse elemento adicionado ao Moodle IMD.

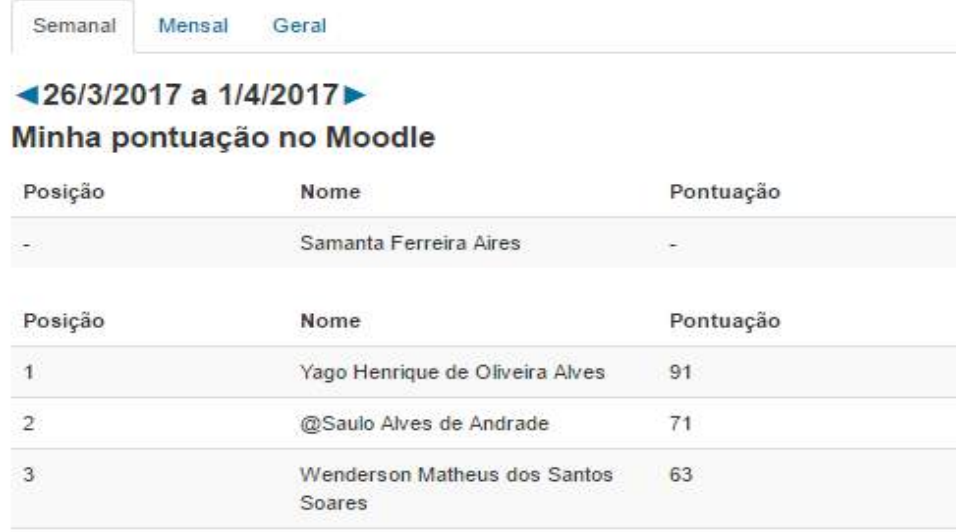

Figura 3. Ranking adicionado ao Moodle IMD.

O sistema de medalhas e o sistema de pontos mais elaborado ainda serão adicionados ao Moodle, mas já estão definidos e prototipados. As medalhas serão dadas aos usuários que realizarem determinadas tarefas dentro do Moodle, por 
exemplo, publicar tópicos, fazer comentários, dar feedback através dos botões, etc. Elas também serão divididas em três categorias: bronze, prata e ouro, e em 5 cinco subcategorias, dependendo da tarefa a ser recompensada. O sistema de pontos será semelhante ao de medalhas, pois os pontos serão dados pela realização de tarefas pré-definidas dentro do sistema e, dependendo da tarefa, esses pontos serão positivos ou negativos. Na Figura 4, apresentamos um protótipo de tela mostrando o perfil do usuário e as medalhas conquistadas por ele.

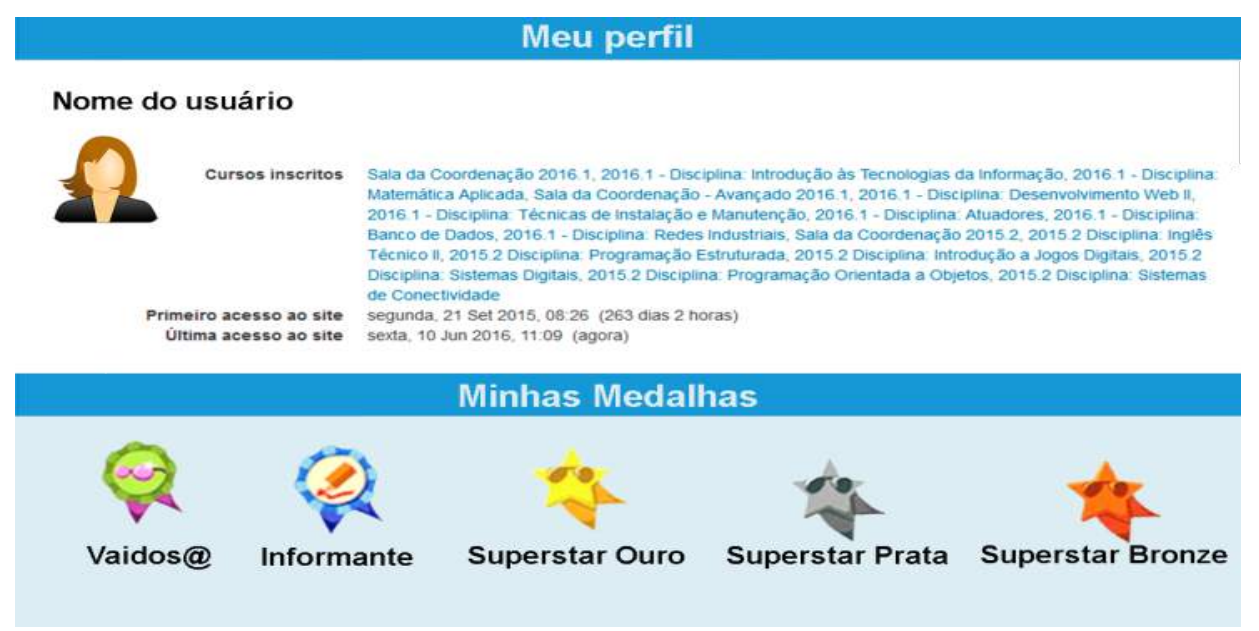

Figura 4. Protótipo de tela mostrando um perfil de usuário e suas medalhas.

\section{Metodologia do estudo}

Para avaliar os efeitos das técnicas introduzidas - botões de reação e ranking buscamos identificar, inicialmente através da coleta e análise de dados, se houve alteração na participação dos alunos após a implantação dos botões de reação aos tópicos e comentários dos principais fóruns do Moodle. Avaliamos também o impacto do ranking indicando a posição de todos os alunos dentro do ambiente virtual.

Para isso, realizamos a coleta dos dados sobre os logs (acesso dos alunos) do Moodle IMD. O log informa todos os passos dados pelos alunos dentro do ambiente virtual Moodle, bem como os tipos de ações realizadas por eles.

Para verificarmos o nível de colaboração dos alunos, definimos que em nosso estudo a colaboração seria medida pela interação e participação dos alunos nos fóruns e ambiente virtual. Com isso, analisamos a interação e participação como sendo o acesso dos usuários ao Moodle e fóruns desse ambiente; as publicações de tópicos; os comentários feitos nos tópicos; as visualizações dos tópicos; e as reações posteriormente realizadas nesses tópicos.

Após definirmos o que analisar, iniciamos a coleta dos dados. Esses dados foram obtidos pelos logs dos alunos do Módulo Intermediário nos semestres 2015.2 e 2016.2. O Módulo Intermediário é o segundo de três semestres que compõem os cursos técnicos. Dessa forma, conseguimos verificar um período de aulas completo, visto que a cada semestre os alunos mudam de turma e de módulo.

No semestre de 2015.2, as turmas do Módulo Intermediário totalizavam 758 
alunos. E em 2016.2 totalizam 763. Os alunos desse módulo cursam 12 disciplinas distintas específicas da ênfase escolhida, podendo ser essa Automação e Eletrônica, Redes, Web; e Jogos; Entretanto, apenas três das doze são disciplinas comuns para todas as ênfases, ou seja, todos os alunos do módulo as cursam.

Escolhemos dois semestres distintos, pois em 2015 ainda não havia sido implantada as técnicas, e dessa forma poderíamos analisar o comportamento dos usuários nos fóruns das disciplinas antes e depois das técnicas.

\section{Análise e Resultados}

A análise do semestre 2015.2 teve como objetivo a verificação dos padrões encontrados nas ações dos alunos dentro do sistema. Já a análise de 2016.2 englobou três estágios distintos, o primeiro mês sem as reações, o segundo e terceiro mês já com o uso das reações e os últimos meses com o uso do ranking. Com a análise desse semestre, buscamos verificar os mesmos dados já analisados no ano anterior, para verificar se houve ou não aumento da interação entre os alunos após a implantação das técnicas. E também realizamos algumas análises específicas sobre o uso das reações.

As análises foram feitas em cima dos fóruns das disciplinas. Cada disciplina possui no mínimo dois fóruns, sendo o Mural de Notícias e o Laboratório de Ideias. Entretanto, se desejar, o tutor pode criar outros fóruns. As disciplinas que escolhemos analisar inicialmente, possuem apenas esses dois fóruns, mas os alunos utilizam apenas o Laboratório de Ideias. Dessa forma, os resultados apresentados abaixo referem-se apenas ao fórum Laboratório de Ideias de cada disciplina.

Com a investigação sobre o número de acessos, pudemos verificar alguns padrões, por exemplo, em quais dias o ambiente virtual é mais acessado; quais os fóruns mais acessados e em quais dias. Esses dados são importantes para a pesquisa, pois com eles podemos levantar algumas hipóteses sobre o uso do ambiente pelos alunos. Nos gráficos 1 e 2 abaixo apresentamos o acesso de duas disciplinas disponibilizadas entre julho e setembro no semestre de 2015.2, sem os botões e no semestre 2016.2, após a implantação dos botões.

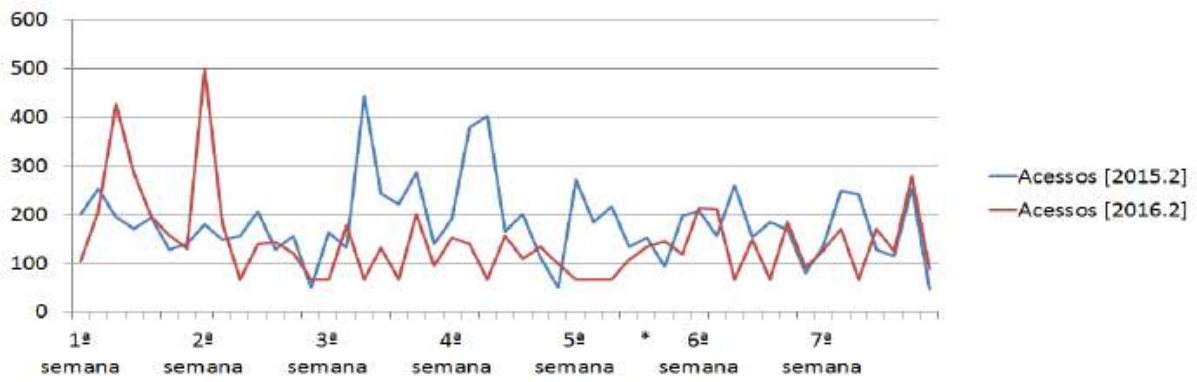

Gráfico 1. Gráfico comparando o número de acessos da disciplina de Inglês Técnico 2 durante os semestres 2015.2 e 2016.2. 


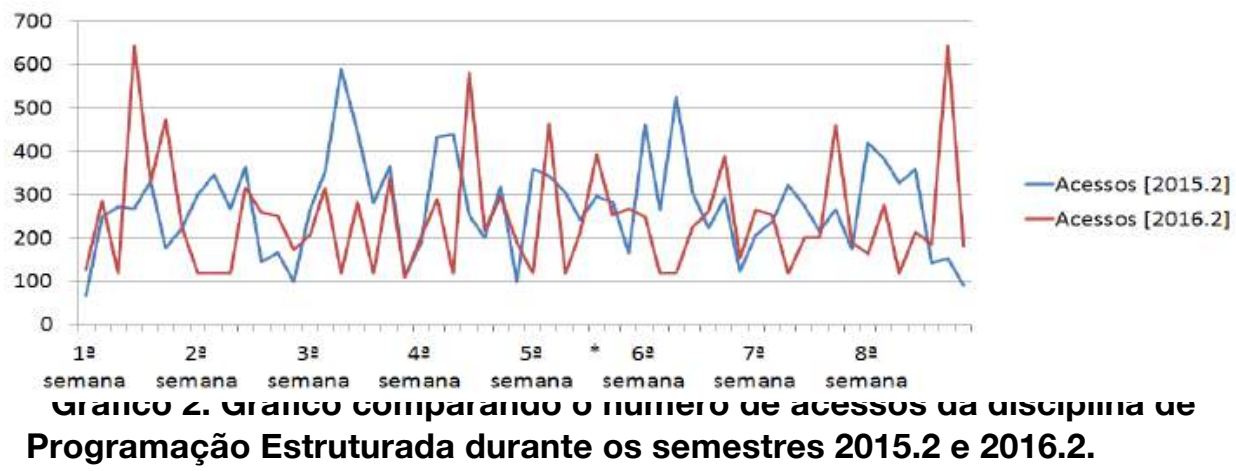

Com a análise dos resultados, que pode ser vista nos gráficos acima, verificamos que o número de acessos aos fóruns dessas disciplinas não sofreram mudança significativa após a introdução dos botões de reações aos fóruns. O asterisco representa o dia da implantação dos botões. Já os gráficos 3 e 4 abaixo apresentam o comparativo dos acessos de três disciplinas após a introdução do bloco de ranking ao sistema Moodle.

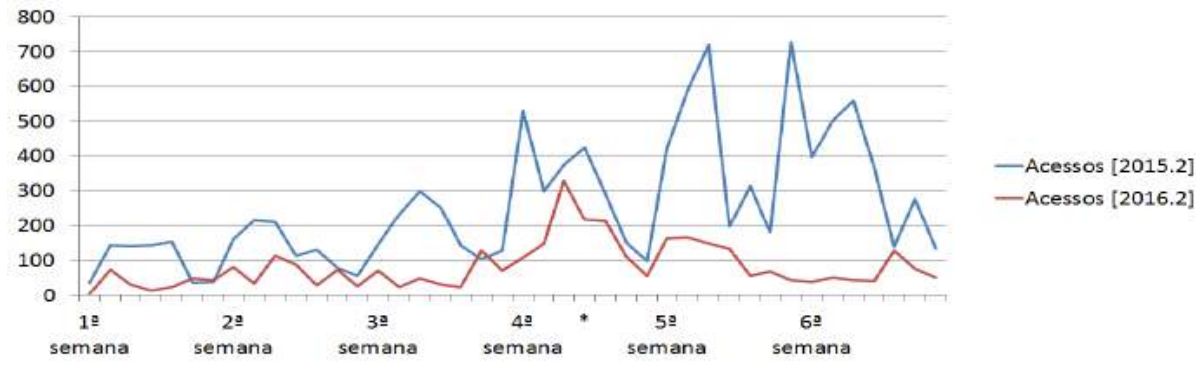

Gráfico 3. Gráfico comparando o número de acessos da disciplina de Desenvolvimento Desktop durante os semestres 2015.2 e 2016.2.

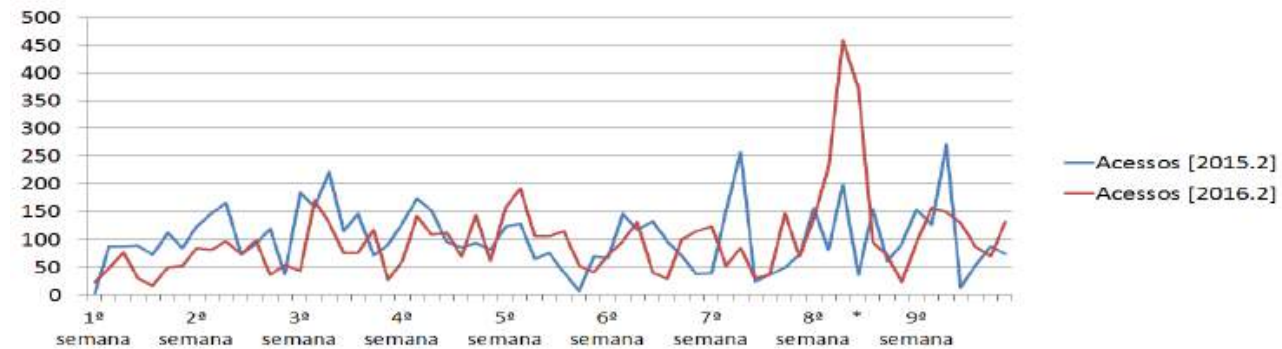

Gráfico 4. Gráfico comparando o número de acessos da disciplina de Autoria Web durante os semestres 2015.2 e 2016.2.

Verificando os acessos das disciplinas após a introdução do Ranking, também não detectamos mudança significativa no número de acessos aos fóruns, como vimos nos gráficos acima. O asterisco representa o dia da adição do Ranking em 2016.2 e, analisando o gráfico percebemos um pico no acesso desse dia, mas logo em seguida o número de acessos volta ao padrão.

O estudo sobre as publicações de tópicos e os respectivos comentários para cada tópico foi importante para verificarmos de fato a interação e participação dos alunos. Com esses dados pudemos analisar padrões sobre o dia em que há mais tópicos publicados e o dia em que há mais comentários, bem como se as publicações são 
realizadas por alunos distintos, ou se apenas um grupo participa, entre outras análises. Os gráficos 5 e 6 representam o número de publicações em algumas disciplinas antes e depois da implantação dos botões. Os gráficos 7 e 8 mostram o número de publicações antes e após a adição do Ranking.

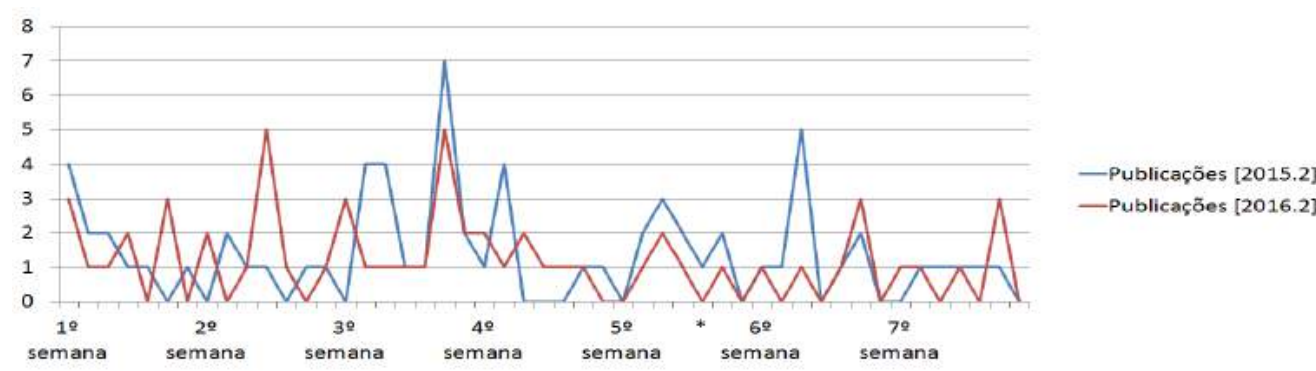

Gráfico 5. Gráfico comparando o número de publicações da disciplina de Inglês Técnico 2 durante os semestres 2015.2 e 2016.2.

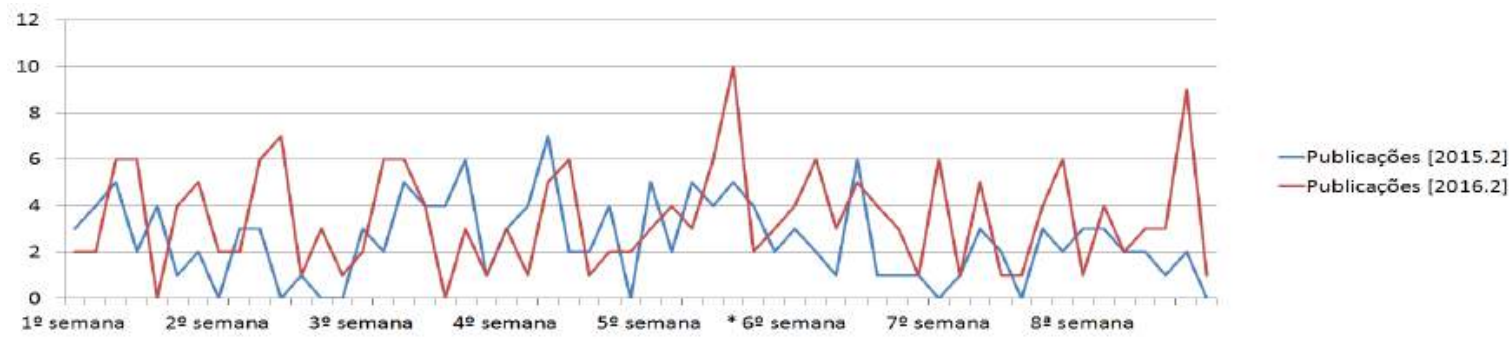

Gráfico 6. Gráfico comparando o número de publicações da disciplina de Programação Estruturada durante os semestres 2015.2 e 2016.2.

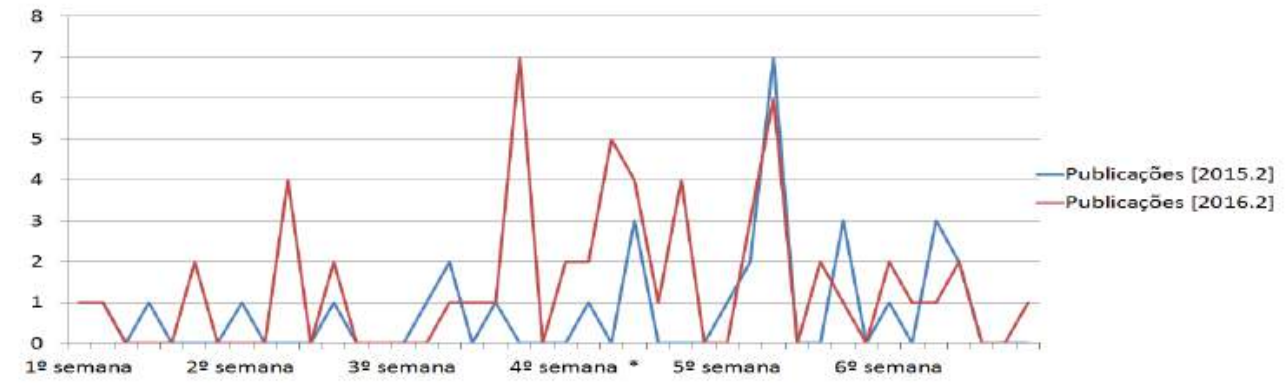

Gráfico 7. Gráfico comparando o número de publicações da disciplina de Desenvolvimento Desktop durante os semestres 2015.2 e 2016.2

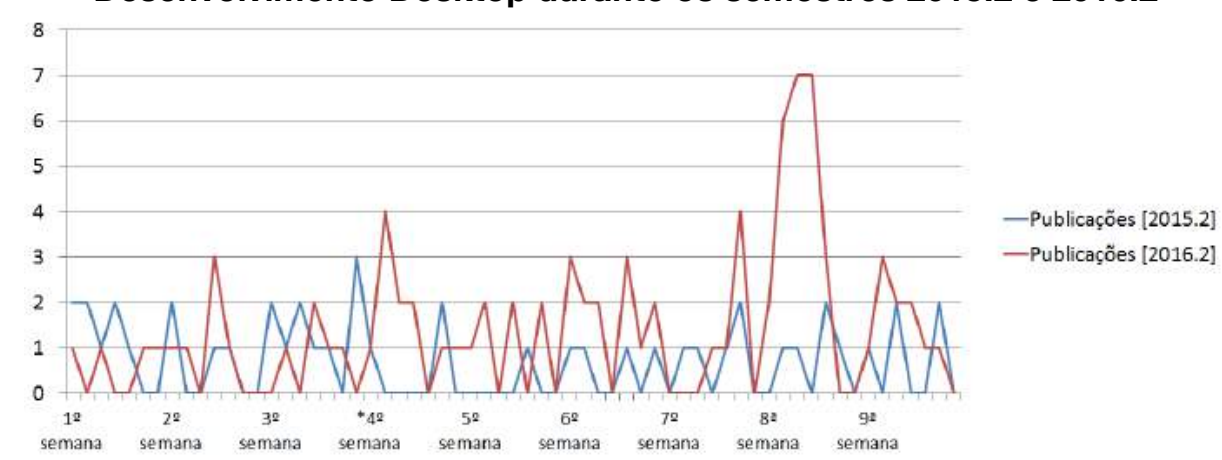

Gráfico 8. Gráfico comparando o número de publicações da disciplina de Autoria Web durante os semestres 2015.2 e 2016.2 . 
Pela análise dos resultados, com alguns sendo apresentados nos gráficos 5, 6, 7 e 8 , verificamos que também não há aumento significativo no número de publicação de tópicos nos fóruns após a adição dos botões e do ranking. Podemos ver que o número de publicações se manteve baixo (entre 1 e 3 ), mas com alguns picos que não estão relacionados aos elementos adicionados.

Uma das análises mais importantes foi do número de comentários. Na etapa de observação verificamos que os alunos costumavam fazer comentários irrelevantes ao conteúdo publicado e a disciplina, por exemplo, abrindo tópicos com "Bom dia, boa tarde, etc", escrevendo comentários apenas com "valeu, obrigado, top". Então esperávamos que, com a adição dos botões de reação, o número de comentários nos tópicos diminuísse, pois esses comentários irrelevantes seriam substituídos pelos botões. Nos gráficos 9 e 10 abaixo apresentamos o comparativo do número de comentários antes e depois da introdução dos botões de reações.

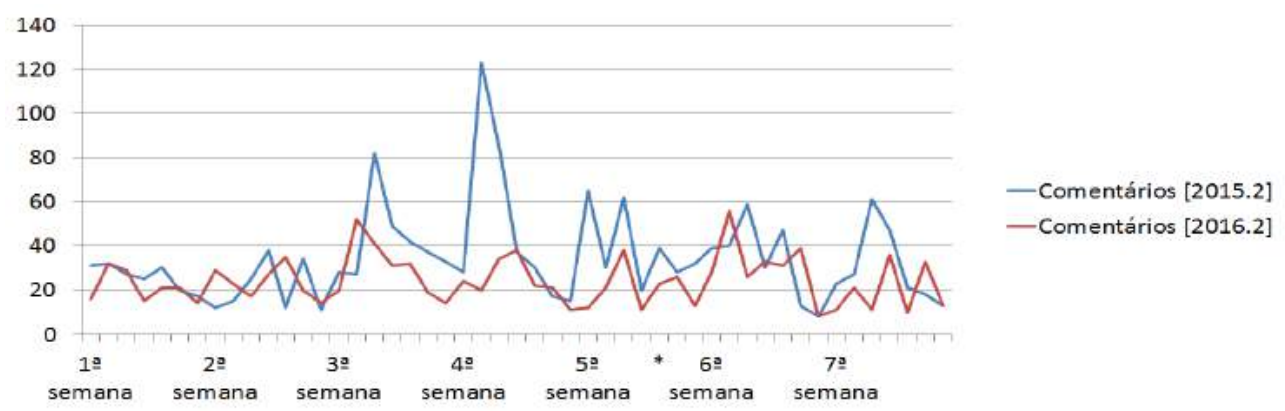

Gráfico 9. Gráfico comparando o número de comentários da disciplina de Inglês Técnico 2 durante os semestres 2015.2 e 2016.2.

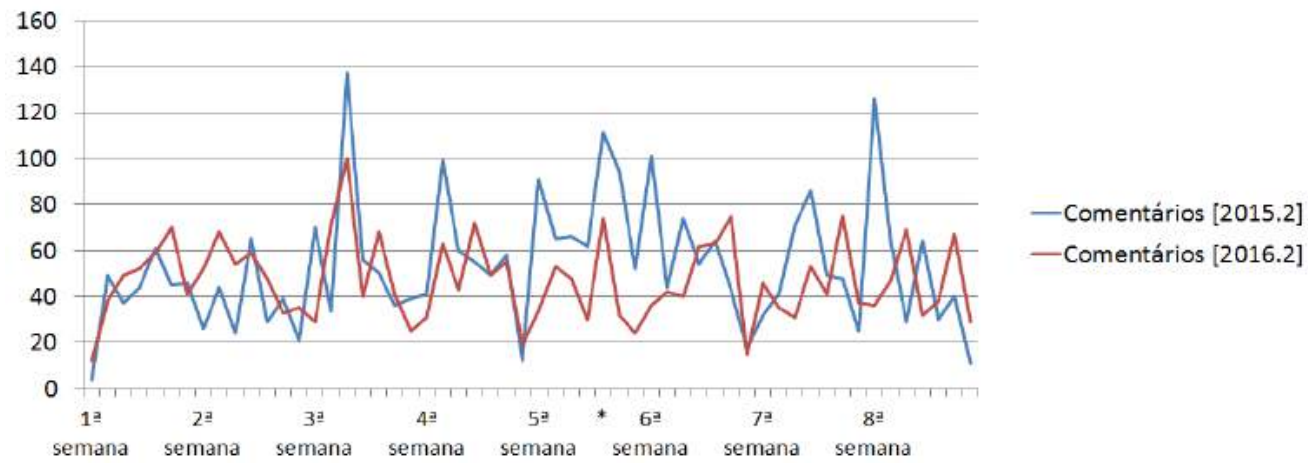

\section{Gráfico 10. Gráfico comparando o número de comentários da disciplina de Programação Estruturada durante os semestres 2015.2 e 2016.2.}

Analisando os comentários, verificamos que também não houve mudanças significativas no número de comentários após a introdução das reações.

Entretanto, quando analisamos o uso das reações, afim de validarmos se os alunos realmente estavam utilizando essa ferramenta, verificamos que elas estão sendo bastante utilizadas, mas que seu uso elevado não diminuiu a quantidade de comentários (gráfico 11), e nem mesmo modificou o tipo de conteúdo dos comentários. 


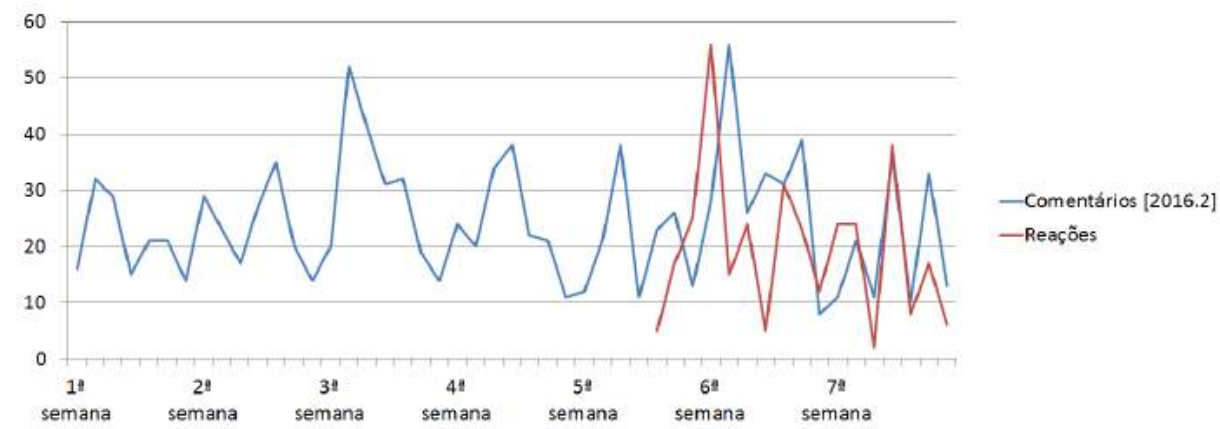

Gráfico 11. Gráfico comparando o número de comentários e de reações da disciplina de Inglês Técnica 2 durante o semestre de 2016.2.

No gráfico 12, verificamos quais as reações mais utilizadas e vemos que o botão "gostei” é o mais usado pelos alunos.

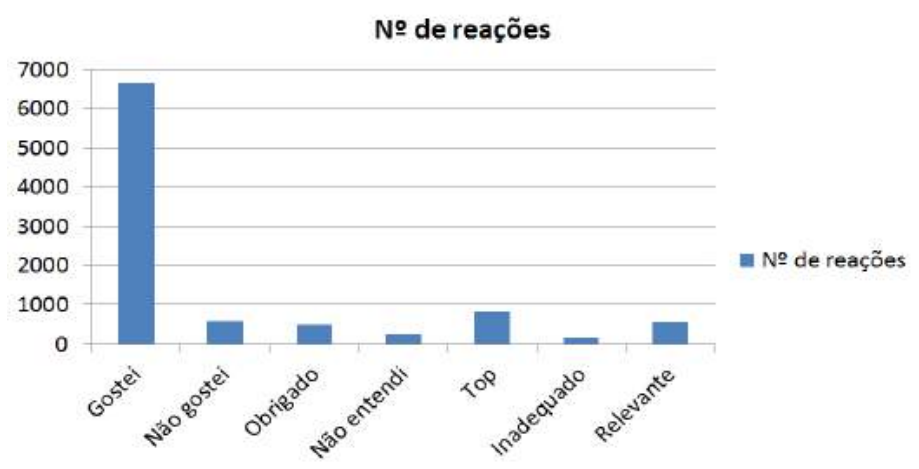

Gráfico 12. Gráfico representando o uso das reações.

\section{Discussão e Conclusão}

Neste artigo mostramos que no contexto de estudos voltados para o estímulo à colaboração e a interação de usuários em sistemas colaborativos, alguns projetos tem como objetivo o uso de mecanismos para motivação de usuários em sistemas no domínio da EAD, como o Moodle.

Neste projeto, em particular, nosso objetivo foi investigar a aplicação de técnicas de motivação que poderiam ser utilizadas para aumentar a interação e a colaboração entre usuários de um sistema. Tomamos então como estudo de caso o Moodle IMD, utilizado pelos cursos técnicos do Instituto Metrópole Digital, da UFRN, e realizamos estudos focados nesse domínio.

Nosso projeto aplicou Técnicas baseadas em reconhecimento e Técnicas baseadas em Recompensas com o objetivo de verificar o aumento da colaboração entre os estudantes. As técnicas baseadas em reconhecimento utilizadas foram os comentários e os botões de reações. Também definimos um sistema de pontos, medalhas e rankings, que são elementos de recompensa. Nesta pesquisa, apenas parte do sistema de pontos e um ranking foi adicionado. 
Nosso estudo mostrou que a aplicação das técnicas não resultou em uma maior interatividade dos alunos usuários do Moodle. Vimos que, mesmo com a adição dos botões e do ranking, não houve aumento de publicações e acessos aos fóruns e nem a diminuição de comentários. Apenas as reações estão sendo bastante utilizadas. Esperava-se um aumento expressivo do uso do sistema tal como ocorre com o interesse dos estudantes pelas redes sociais que já havia sido detectado em um estudo anterior. Entretanto, não conseguimos um resultado que confirmasse essas expectativas. Ao mesmo tempo, não podemos afirmar que é um resultado negativo.

Sabemos que esses elementos são considerados fatores motivacionais, mas a aplicação deles deve sempre estar de acordo com os objetivos do sistema, principalmente quando falamos de fóruns e dos botões de reações. Esses elementos devem estar especialmente relacionados ao domínio do sistema. Além disso, cada um oferece vantagens e desvantagens quanto a sua utilização e, deve-se escolher qual melhor se aplicaria ao seu sistema, podendo-se utilizar apenas um, ou o conjunto.

O que podemos interpretar dos resultados é:

- Um AVA como o Sistema Moodle não é uma rede social e não se pode afirmar que o que funciona nas redes terá o mesmo efeito num sistema de EAD.

- Os elementos de gamificação (ranking e pontuação) que introduzimos não surtiram o efeito desejado neste estudo inicial. Vamos continuar os resultados e realizar alterações, além de introduzir medalhas. Dentre as alterações futuras espera-se associar a pontuação não apenas com a participação social, mas com aspectos relacionados à aprendizagem.

- A introdução das técnicas escolhidas não fizeram alterações significativas no design de interação do Moodle que já existia. Por exemplo, não foram alteradas as salas e os fóruns. Precisamos considerar que as técnicas poderiam ser melhor aplicadas com alguns ajustes nos fóruns existentes e outras mudanças na interface.

O importante do nosso estudo é desmitificar fatos de que técnicas como a gamificação ou mesmo a aplicações dos botões que deram certo no Facebook são soluções imediatas. Nossa conclusão é que qualquer técnica com este propósito precisa ser estudada e usada de forma apropriada.

O próximo passo dessa pesquisa é a implantação do sistema de pontos mais completo e do sistema de medalhas. Esperamos que os resultados obtidos com essas novas técnicas sejam positivos e que resultem num aumento de colaboração entre os alunos.

\section{Referências}

Alves, F. P..; Maciel, C. M.; Alonso, K. M. (2013). “A utilização de badges no ambiente virtual de aprendizagem Moodle". Em: Seminário Nacional de Inclusão Digital, 2014, Passo Fundo - RS. Anais do III Seminário Nacional de Inclusão Digital. Passo Fundo - RS: Ed. Universidade de Passo Fundo, 2014.

Deterding, S.; Dixon, D.; Khaled, R; Nacke, L. (2011). "From game design elements to 
gamefulness: defining 'gamification'". Em: Proceedings of the 15th International Academic MindTrek Conference: Envisioning Future Media Environments.

Faleiros, F. P.; Almeida, B. S. R. (2015). "Interface e Ferramentas do Moodle: a experiência do usuário em práticas colaborativas gamificadas". Disponível em: http://www.periodicos.letras.ufmg.br/index.php/anais_linguagem_tecnologia/article/ view/8453.

Fardo, M. (2013). “A Gamificação Aplicada Em Ambientes De Aprendizagem”. Em: . RENOTE. Revista Novas Tecnologias na Educação , v. 11, p. 1, 2013.

Grant, S.; Betts, B. (2013). "Encouraging user behaviour with achievements: An empirical study". Em: Mining Software Repositories (MSR), 2013 10th IEEE Working Conference. Disponível em: http://ieeexplore.ieee.org/abstract/document/6624007/?reload=true.

Hamari, J. and Koivisto, J. (2013). "Social motivations to use gamification: an empirical study of gamifying exercise". Em: Proceedings of the 21st European Conference on Information Systems.

Ferreira, J. L. (2013). "Moodle: Um espaço de interação e aprendizagem". Em: Educação a Distância no Brasil: aspectos históricos, legais, políticos e metodológicos.

Knihs, E.; Araújo, J. (2007). "Cooperação e Colaboração em Ambientes Virtuais de Aprendizagem Matemática". Disponível em: http://alb.com.br/arquivomorto/edicoes_anteriores/anais16/sem15dpf/sm15ss10_02.pdf.

Mehlecke, Q. T. C.; Tarouco, L. M. R. A. (2011). “Ambientes de suporte para educação à distância: a mediação para aprendizagem cooperativa”. Em: Ciclo de Palestras sobre Novas Tecnologias na Educação , Porto Alegre - RS, v. 1, 2003.

Roque, A. S..; Geiss, E. R.; Santos, C. P.; da Silva; D. R. (2013). "Técnicas de Gamificação em AVAs: Um Estudo de Caso no Ambiente Virtual de Aprendizagem Moodle". Disponível em: http://www.eati.info/eati/2013/assets/anais/artigo53.pdf. 